Supplementary Material

\title{
Electrochemical one-step immunoassay based on switching peptides and pyrolyzed carbon electrode
}

Jun-Hee Park a,\#, Zhiquan Song a,\#, Ji-Hong Bong a, Hong-Rae Kim a , Moon-Ju Kim a,

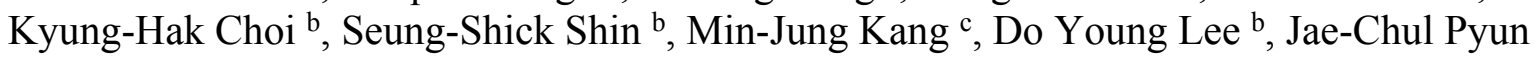
a,*

\footnotetext{
a Department of Materials Science and Engineering, Yonsei University, 50 Yonsei-Ro, Seodaemungu, Seoul (03722), Korea Tel: +82 22123 5851/Fax: +82 23125375

${ }^{\mathrm{b}}$ OPTOLANE Technologies Inc., 20 Pangyoyeok-ro 241beon-gil, Bundang-gu, Seongnam-si, Gyeonggi-do, 13494, Republic of Korea

${ }^{\mathrm{c}}$ Korea Institute of Science and Technology (KIST), 5 Hwarang-ro 14-gil, Seongbuk-gu, Seoul, 02792, Republic of Korea

\# These authors contributed equally to this work.
} 


\section{口 EXPERIMENTAL SECTION}

\section{Materials}

Ferrocene, potassium bromide, bovine serum albumin (BSA), dimethyl sulfoxide (DMSO), Tween-20, and normal human serum were purchased from Sigma-Aldrich (Seoul, Korea). Phosphate-buffered saline (PBS) was purchased from Curebio (Seoul, Korea). hHBsAg enzyme-linked immunosorbent assay (ELISA) kits were purchased from INVIBIO (Beijing, China). $\mathrm{Ag} / \mathrm{AgCl}$ pellet-formed reference electrodes were purchased from Warner Instruments LLC (Hamden, CO, USA). A Pt wire electrode was used as a counter electrode in a threeelectrode system for CV and DPV. Ferrocene-labeled switching peptides were synthesized by Peptron (Daejeon, Korea).

\section{Deposition and Pyrolysis of Parylene-C}

Parylene-C films were prepared using the conventional thermal deposition method, as reported previously. ${ }^{1}$ Parylene-C films were prepared using a commercial parylene deposition system from Femto Science (Hwaseong, Korea). Parylene-C film deposition involved three steps: (1) evaporation of parylene-C dimers at $160{ }^{\circ} \mathrm{C}$; (2) pyrolysis of the parylene-C dimer gas at $650{ }^{\circ} \mathrm{C}$ to transfer the dimers into monomers; and (3) monomer polymerization at ambient temperature. These steps were performed under vacuum $(<5.3 \mathrm{~Pa}(40 \mathrm{mTorr}))$. The parylene-C film thickness was controlled by varying the amount of parylene-C dimer. Parylene-C pyrolysis was performed in a vacuum furnace at $900{ }^{\circ} \mathrm{C}$ for $1 \mathrm{~h}$ in an $\mathrm{N}_{2}$ atmosphere (20 mTorr).

\section{Characterization of the Parylene-C Films}

Atomic force microscopy from Park System (model: XE-100, Seoul, Korea) was used to measure the thickness and surface roughness of the parylene-C film and pyrolyzed carbon film. The samples for surface roughness measurement were prepared by coating the films on an $\mathrm{Si}$ wafer $\left(1.0 \times 1.0 \mathrm{~cm}^{2}\right)$. The thickness of the film was then measured by scratching the films. The crystal structure of the parylene- $\mathrm{C}$ dimer, parylene-C film, and pyrolyzed carbon film were characterized using high-resolution XRD (Rigaku, Tokyo, Japan). A Cu-K $\alpha$ X-ray source with a power of $9 \mathrm{~kW}$ was used. The glancing angle was set to $\theta=1^{\circ}$ against the incident beam, and the scan rate was $2 \theta=2 \% \mathrm{~min}$. The surface molecular structures of the parylene-C film and pyrolyzed carbon film were analyzed using an FT-IR spectrometer (PerkinElmer Co, Waltham, MA, USA). The parylene-C film (1 $\mu \mathrm{m})$ was coated on the KBr pellet, and the FT-IR spectrum was obtained in transmission mode. For the pyrolyzed carbon film, a parylene-C film $(10 \mu \mathrm{m})$ was coated on a silicon wafer and pyrolyzed to a thickness of $1 \mu \mathrm{m}$, and the FT-IR spectrum was obtained in the attenuated total reflection (ATR) mode. ${ }^{1-3}$ The surface structure and elemental composition of the parylene-C film and pyrolyzed carbon film were analyzed using XPS (model: Kalpha) from Thermo VG (East Grinstead, UK). The substrates of the XPS samples were Si wafers with a thickness of $100 \mathrm{~nm} \cdot{ }^{4-5}$ The changes in the molecular structure of parylene-C and pyrolyzed carbon films $(100 \mathrm{~nm}$ on an $\mathrm{Si}$ wafer) were also determined using a Raman spectrometer (LabRam Aramis) from Horiba Jobin Yvon (Kyoto, Japan) with an Nd: YAG laser at $532 \mathrm{~nm}^{6-8}$ 


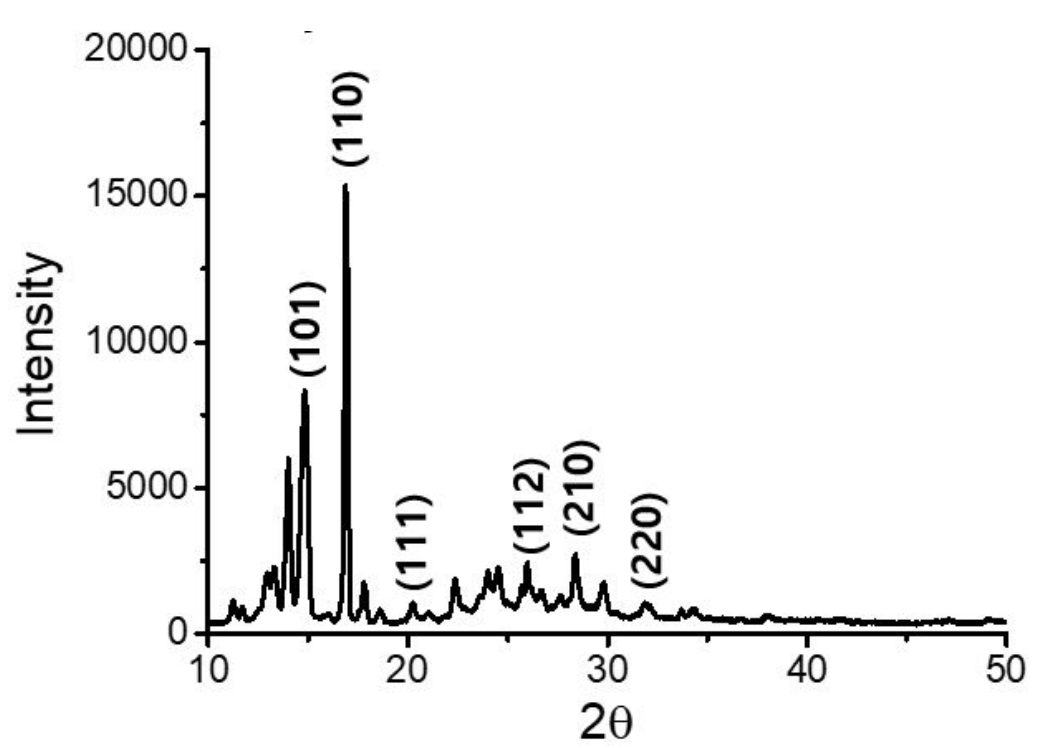

Figure S1. XRD spectrum of parylene-C dimer.

\section{Electrochemical Analysis}

Cyclic voltammetry and differential pulse voltammetry were performed using a potentiostat (IVIUM Technologies, Eindhoven, Netherlands). The CV method was performed at a scan rate of $50 \mathrm{mV} / \mathrm{s}$ with $10 \mathrm{mV}$ step potential in the potential range of -0.5 to $0.5 \mathrm{~V}$ versus the $\mathrm{Ag} / \mathrm{AgCl}$ reference electrode. The DPV was conducted at a scan rate of $50 \mathrm{mV} / \mathrm{s}$ with pulse time of $20 \mathrm{~ms}$ in the range of $-0.4-0.7 \mathrm{~V}$ versus the $\mathrm{Ag} / \mathrm{AgCl}$ reference electrode. The signal was estimated to be the current at a potential of $0.1 \mathrm{~V}$ versus $\mathrm{Ag} / \mathrm{AgCl}$. Ferrocenelabeled switching peptides ( $\mathrm{L} 1$ and $\mathrm{H} 2$ ) ranging from $1 \mathrm{nM}-10 \mu \mathrm{M}$ were quantitatively analyzed using DPV. Each peptide was dissolved in DMSO (1 mM) and diluted with PBS owing to the hydrophobic properties of the peptides. Differential pulse voltammetry was performed in the potential range of -0.2 to $0.6 \mathrm{~V}$ versus the $\mathrm{Ag} / \mathrm{AgCl}$ reference electrode. The signal was estimated at a potential of $0.05 \mathrm{~V}$ versus the $\mathrm{Ag} / \mathrm{AgCl}$ reference electrode. 


\section{Electrochemical properties of pyrolyzed carbon electrode}

The electrochemical properties of the pyrolyzed carbon electrode were estimated for the apparent electron transfer rate $\left(\mathrm{k}_{\mathrm{app}}\right)$, double layer capacitance $\left(\mathrm{C}_{\mathrm{dl}}\right)$, and electrochemical window. The apparent rate constant for electron transfer $\left(\mathrm{k}_{\text {app }}\right)$ was estimated for the carbon electrode following pyrolysis of the parylene-C film. The apparent rate constant for electron transfer was measured using cyclic voltammetry in $100 \mu \mathrm{M}$ ferrocene and $1 \mathrm{M}$ $\mathrm{KCl}$ according to the Nicholson method. ${ }^{9-10}$ In this method, the separation between the cathodic peak potential $\left(E_{\mathrm{cp}}\right)$ and anodic peak potential $\left(\mathrm{E}_{\mathrm{ap}}\right)$ was estimated according to the scan rates, as shown in Figure S2a. The rate constant for electron transfer $\left(k_{\text {app }}\right)$ of the pyrolyzed carbon electrode was $0.0054 \mathrm{~cm} \cdot \mathrm{s}^{-1}$ from the peak potential separation $\left(\Delta \mathrm{E}_{\mathrm{p}}\right)$ between the cathodic and anodic peaks in the cyclic voltammograms at different scan rates. Usually, metal electrodes exhibit fast electron transfer kinetics for many redox systems. In fact, the reported rate constants for the electron transfer of $\mathrm{Au}$ and $\mathrm{Pt}$ were $\mathrm{Au}=0.07-0.10$, and $\mathrm{Pt}=0.21 \mathrm{~cm} \cdot \mathrm{s}^{-1} .9,11$ The rate constant for the electron transfer $\left(\mathrm{k}_{\mathrm{app}}\right)$ of carbon electrodes is lower than that for metal electrodes, such as glassy carbon $=0.0066$, graphite $=0.000001$, and diamond-like carbon $($ DLC $)=0.012 \mathrm{~cm} \cdot \mathrm{s}^{-1} .9,12$ These results indicate that the pyrolyzed carbon electrode $\left(0.0054 \mathrm{~cm} \cdot \mathrm{s}^{-1}\right)$ had a $\mathrm{k}_{\text {app }}$ value in a range similar to that of a typical carbon electrode.

The double layer capacitance $\left(\mathrm{C}_{\mathrm{dl}}\right)$ was estimated for the pyrolyzed carbon electrode using cyclic voltammetry. ${ }^{9}$, ${ }^{13}$ The double layer capacitance could be estimated from the charging current (non-faradaic current) on the electrode surface by analyzing the cyclic voltammograms at different scan rates: $i=C \cdot(d V / d t)$, where $i$ is the current density $\left(\mathrm{A} / \mathrm{cm}^{2}\right)$ and $\mathrm{C}$ is the capacitance $(\mathrm{C})$. Therefore, $\mathrm{C}_{\mathrm{dl}}$ was calculated as the surface capacitance corresponding to the slope of the plot of the current magnitudes for the series of cyclic voltammograms at a given potential $\left(0 \mathrm{~V}\right.$ in this study). ${ }^{13}$ To avoid the overwhelming faradaic current from any redox couple, phosphate buffered saline (PBS) was used as the electrolyte. ${ }^{9}$ The estimated double layer capacitance of the pyrolyzed carbon electrode was $2.10 \mu \mathrm{F} / \mathrm{cm}^{2}$ (Figure S2b). This double layer capacitance value was significantly lower than that of metal electrodes, such as $\mathrm{Au}\left(30.9 \mu \mathrm{F} / \mathrm{cm}^{2}\right), \operatorname{Pt}\left(64.2 \mu \mathrm{F} / \mathrm{cm}^{2}\right), \operatorname{Ag}\left(52.6 \mu \mathrm{F} / \mathrm{cm}^{2}\right)$, and stainless steel $\left(39.8 \mu \mathrm{F} / \mathrm{cm}^{2}\right)$ but similar to that of the graphite electrode $\left(4.78 \mu \mathrm{F} / \mathrm{cm}^{2}\right) .{ }^{14-15}$ Such findings imply that the pyrolyzed carbon electrode could have a lower background current of $\mathrm{i}-\mathrm{V}$ curves than metal electrodes and conventional graphite electrode due to the decreased double layer capacitance.

The electrochemical window of the pyrolyzed carbon electrode was compared to that of the Au and conventional graphite electrodes. For the pyrolyzed carbon electrode, the electrochemical window between the oxidation of oxygen and the reduction of hydrogen was estimated to be between -0.9 and $+1.6 \mathrm{~V}$ against the $\mathrm{Ag} / \mathrm{AgCl}$ reference electrode. The electrochemical window is often estimated to be between -0.3 and $+0.7 \mathrm{~V}$ for the Au-electrode, and -0.5 and $+1.6 \mathrm{~V}$ for graphite-electrode against $\mathrm{Ag} / \mathrm{AgCl}$ reference electrode, as shown in Figure $\mathrm{S} 2 \mathrm{c} .{ }^{16-17}$ Therefore, the findings of the present study indicate that the pyrolyzed carbon electrode could be effectively used in the electrochemical immunoassay with a sufficient electrochemical window. 
Figure S2. Electrochemical properties of pyrolyzed carbon electrode. (a) Estimation of the electron transfer rate $\left(\mathrm{k}_{\mathrm{app}}\right)$, (b) Estimation of the double layer capacitance $\left(\mathrm{C}_{\mathrm{dl}}\right)$ of the pyrolyzed carbon electrode. (c) Comparison of the electrochemical window for $\mathrm{Au}-$, graphite, and pyrolyzed carbon electrodes.

(a)

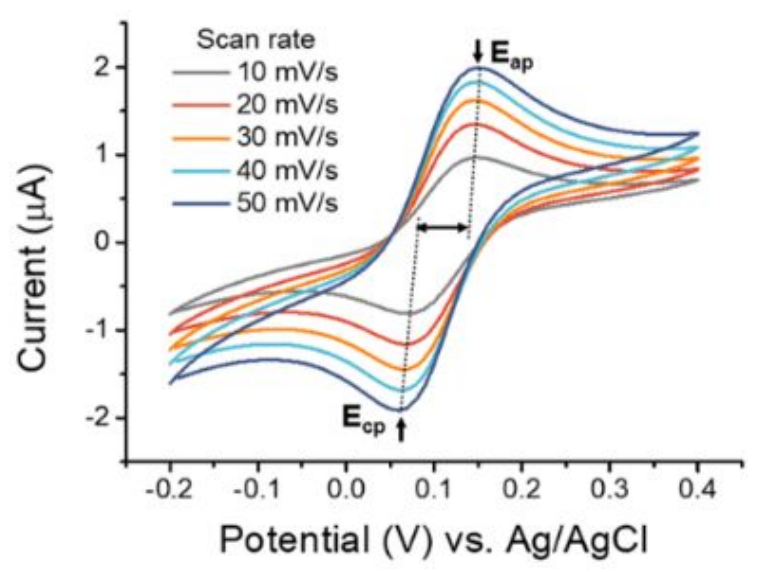

(b)

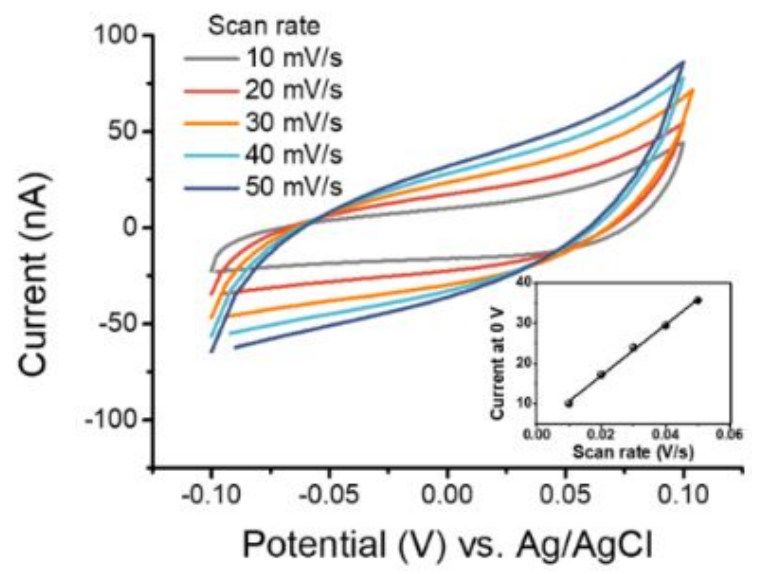

(c)

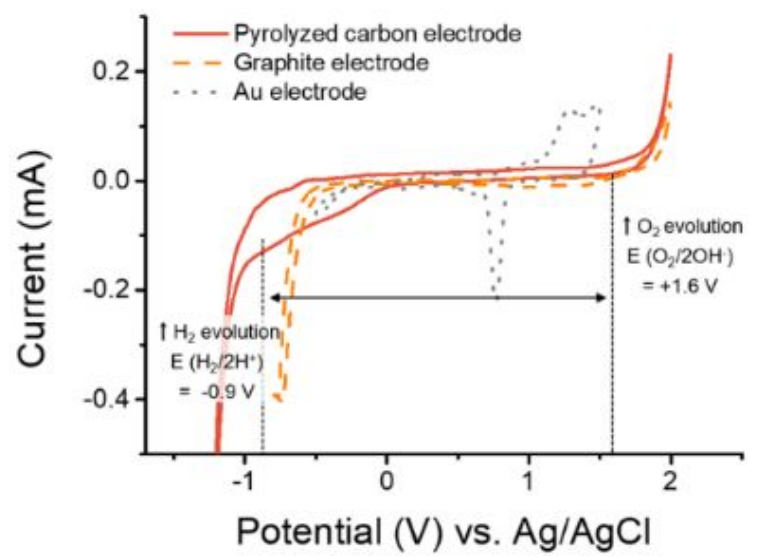




\section{Electrochemical Properties of Ferrocene-labeled Switching Peptides.}

In the electrochemical one-step immunoassay, ferrocene-labeled switching peptides were analyzed using amperometry with cyclic voltammetry (CV) or differential pulse voltammetry (DPV). First, ferrocene was analyzed using a pyrolyzed carbon electrode. As shown in Figure 3a, $1 \mathrm{nM}-400 \mu \mathrm{M}$ of ferrocene was analyzed using CV and DPV. The signal current was obtained from the peak current at the anodic wave of the CV as well as the peak current of the DPV. As the pyrolyzed carbon electrode was found to have a lower double layer capacitance $\left(\mathrm{C}_{\mathrm{dl}}\right)$ of $2.10 \mu \mathrm{F} / \mathrm{cm}^{2}$, the background signal from the $\mathrm{i}-\mathrm{V}$ measurement was observed to be lower than that of the metal electrode (i.e., Au electrode, $30.9 \mu \mathrm{F} / \mathrm{cm}^{2}$ ). Amperometry based on DPV is known to decrease the background signal to minimize the charging current of the electrode relative to $\mathrm{CV}$, which continuously changed the potential to the electrode. ${ }^{18-19}$ In comparison with Au electrode (Figure S3), the limit of detection (LOD) was estimated to be improved to be $100 \mathrm{nM}$ with pyrolyzed parylene electrode ( $10 \mu \mathrm{M}$ with Au electrode) for $\mathrm{CV}$ as well as $10 \mathrm{nM}$ with pyrolyzed parylene electrode ( $1 \mu \mathrm{M}$ with Au electrode) for DPV analysis. Further, the dynamic range for DPV analysis was estimated to range from $10-10^{4} \mathrm{nM}$ with a linearity factor $\left(\mathrm{R}^{2}\right)$ of 0.964 . These results indicate that the pyrolyzed carbon electrode based on DPV can effectively measure ferrocene. Four types of switching peptides labeled with ferrocene (L1, H2, L2, and H1) were analyzed with a pyrolyzed carbon electrode. The concentration of the four switching peptides and ferrocene was maintained at $10 \mu \mathrm{M}$ while the scan rate was maintained at $50 \mathrm{mV} / \mathrm{s}$ in the potential range of -0.2 to $0.8 \mathrm{~V}$ against $\mathrm{Ag} / \mathrm{AgCl}$ reference electrode. As shown in Figure 3b, based on the CV results, the current signal of ferrocene was the highest among the other analytes (i.e., $-1.5 \mu \mathrm{A}$ from cathodic wave, $\mathrm{E}_{\mathrm{cp}}=0.1 \mathrm{~V}$ vs $\mathrm{Ag} / \mathrm{AgCl}$ reference electrode, and $2.1 \mu \mathrm{A}$ from the anodic wave, $\mathrm{E}_{\mathrm{ap}}=0.2 \mathrm{~V}$ vs $\mathrm{Ag} / \mathrm{AgCl}$ reference electrode). The four types of switching peptides labeled with ferrocene showed two features: (1) lower peak current and (2) migration of potentials at peak currents. Among the four types of switching peptides, the CV results showed that the L1- and H2-switching peptides had similar peak currents and potentials at peak currents compared with the L2- and H1-switching peptides. Based on the DPV results shown in Figure 3c, the current signal of ferrocene was estimated to be the highest among the analytes (i.e., $0.94 \mu \mathrm{A} ; \mathrm{E}_{\mathrm{ap}}=0.1 \mathrm{~V}$ against the $\mathrm{Ag} / \mathrm{AgCl}$ reference electrode). Similar to the results of $\mathrm{CV}$ analysis, the four types of switching peptides labeled with ferrocene showed two features: (1) lower peak current and (2) migration of potentials at peak currents. The L1- and H2-switching peptides had relatively similar peak currents and potentials at peak currents compared with the L2- and H1-switching peptides. For the L1- and H2-switching peptides, the full width at half maximum (FWHM) was lower than that of ferrocene. These results indicate that the different physical and chemical properties of the four types of switching peptides influenced the electrochemical properties of CV and DPV. 
Figure S3. Analysis of ferrocene with cyclic voltammetry (CV) and differential pulse voltammetry (DPV) using Au-electrode.
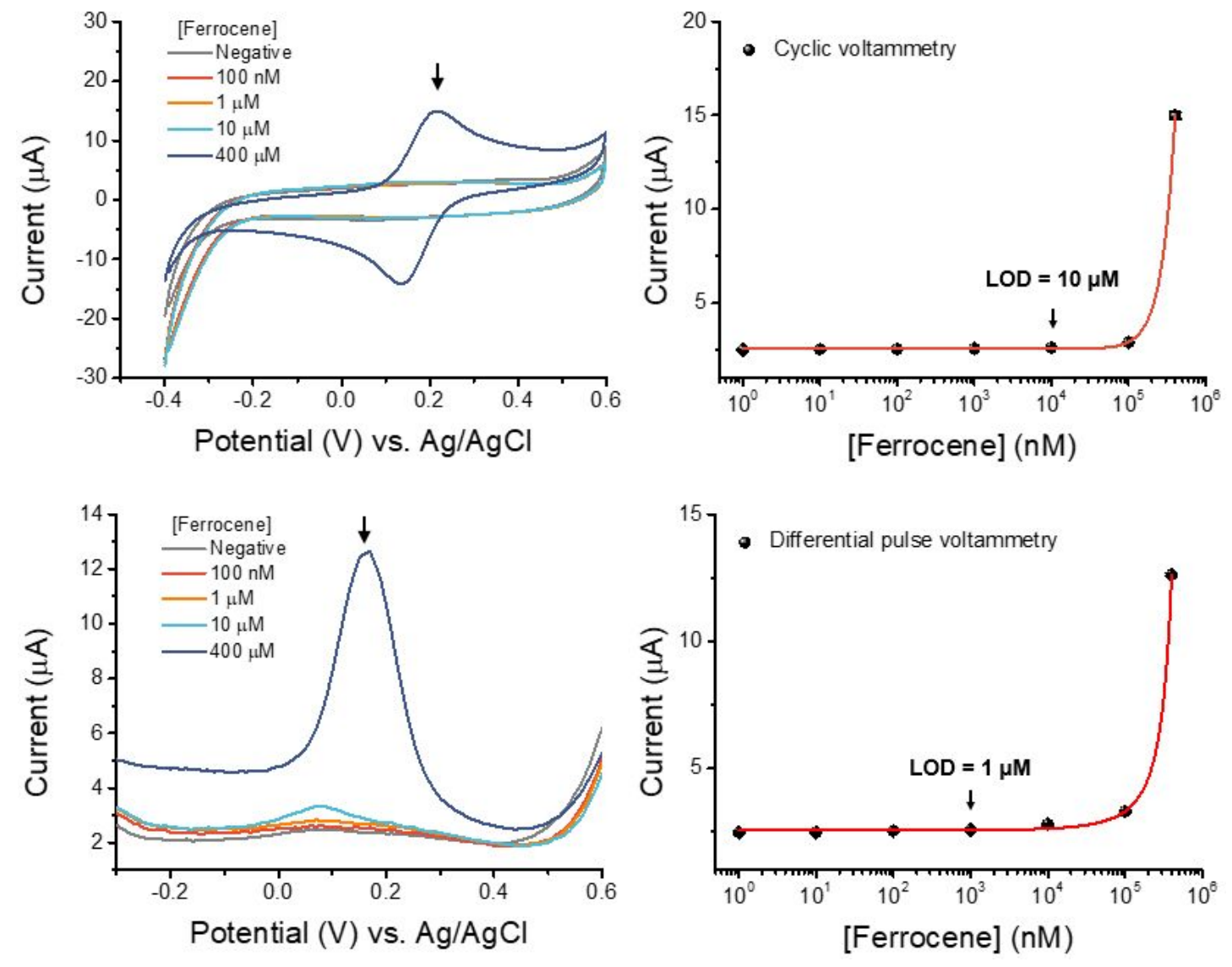


\section{Estimation of diffusion constant}

Based on the CV analysis of four kinds of switching peptides at different scan rates (Figure S4), the diffusion coefficient could be estimated as shown in Figure 4c. The diffusion coefficient was calculated using RandlesSevcik equation: $\left(\frac{\mathrm{i}_{\mathrm{p}}}{\sqrt{\mathrm{v}}}\right)=2.7 \times 10^{5} \cdot \mathrm{n}^{\frac{3}{2}} \cdot \mathrm{A} \cdot \sqrt{\mathrm{D}_{\mathrm{ox}}} \cdot \mathrm{C}$, where $\mathrm{n}$ is the number of moles of electrons transferred per mole of electroactive species, $\mathrm{A}$ is the area of the electrode, and $\mathrm{C}$ is the concentration of the electroactive species. ${ }^{20}$ Such difference in diffusion coefficients suggests that over- potential could occur according to the Nernst equation for an irreversible process: $E=E_{0}{ }^{\prime}+\eta+\frac{R T}{n F} \ln \frac{C_{R}}{C_{0}}, \eta=A \times \log \left(i / i_{0}\right)$ where $\eta$ represents overpotential and A represents "Tafel slope."20-23

Figure S4. CV analysis of four kinds of switching peptides at different scan rate for the estimation of diffusion coefficient: (a) L1-Fc, (b) H2-Fc, (c) L2-Fc, (d) H1-Fc.

(a)

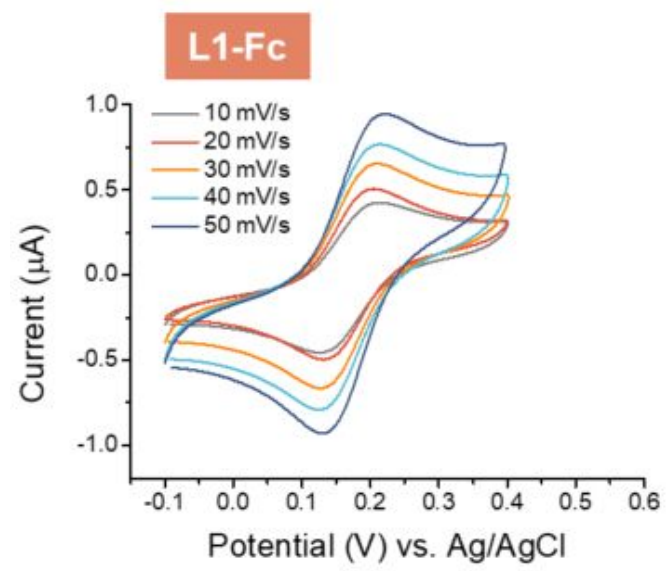

(c)

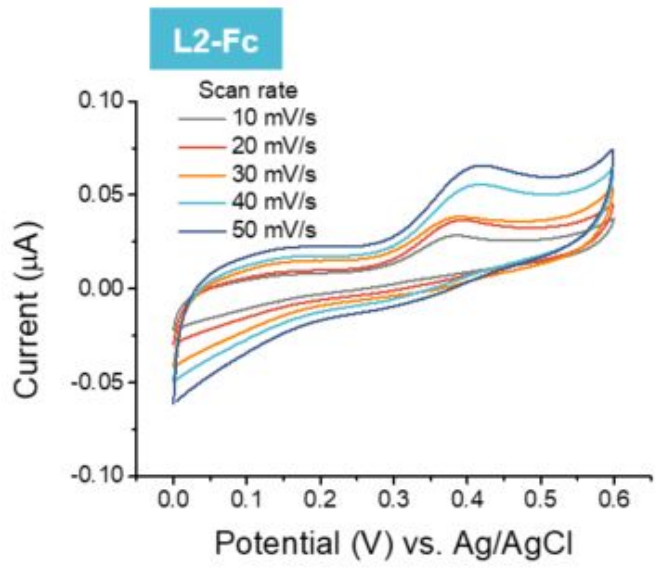

(b)

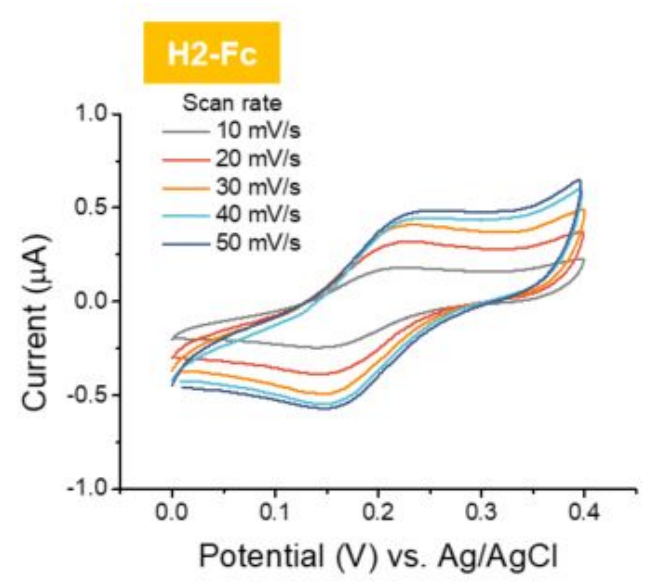

(d)

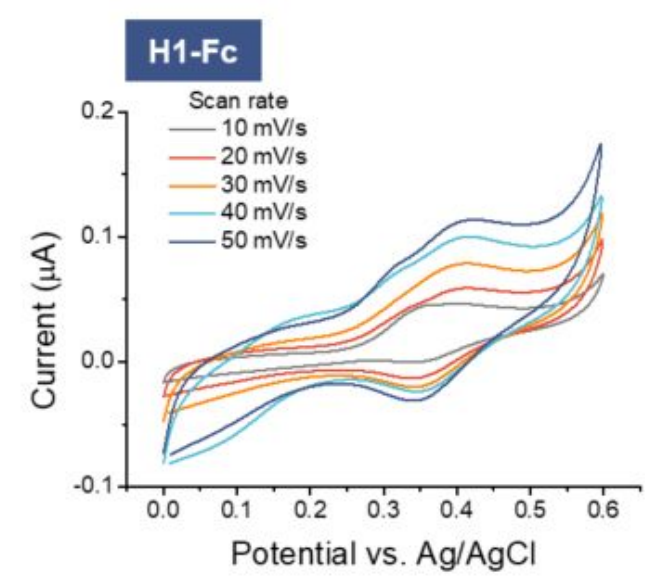




\section{- One-step Immunoassay based on Switching Peptides}

The electrochemical one-step immunoassay of hHBsAg was carried out using PBS and spiked samples in normal human serum. MAXIsorp was coated with an anti-hHBsAg antibody at a concentration of $20 \mu \mathrm{g} / \mathrm{ml}$ for $2 \mathrm{~h}$. BSA was used as a blocking agent to prevent non-specific adsorption. Ferrocene-labeled switching peptides (L1 and $\mathrm{H} 2)$ were incubated at a concentration of $10 \mu \mathrm{M}(100 \mu \mathrm{l} /$ well $)$ for $1 \mathrm{~h}$. After incubation, standard hHBsAg samples ranging from $1 \mathrm{ng} / \mathrm{ml}-1 \mu \mathrm{g} / \mathrm{ml}$ were used with a dilution factor of 3 . The hHBsAg test was validated according to the manufacturer's protocol using the standard calibrator in the commercial kit from Innovation Biotech (Beijing, China). The medical diagnosis of hHBsAg was carried out by using the cutoff value for determining the positive sample. According to the manufacturer's instruction, the determination of samples to be positive and negative was carried out using a cutoff value which was established from the test results with a negative sample: cutoff $=2.1 \times \mathrm{OD}$ at $450 \mathrm{~nm}$ for negative control $(\mathrm{AU})$. The concentration of hHBsAg at the cutoff value was corresponded to be $400 \mathrm{ng} / \mathrm{ml}$ in human serum. As described in the manufacturer's instruction, the cutoff value was established from 10,980 healthy blood donors and 300 hospitalized patients. The test indicated $99.6 \%$ specificity for the patients' sample. The clinical sensitivity was evaluated by samples obtained from 1,120 hepatitis B patients with well-noted clinical history for detection of hHBsAg. The test demonstrated $99.8 \%$ sensitivity for acute patients and $99.3 \%$ sensitivity for chronic patients. The validation of the test results was carried out using positive and negative samples included in the test kit using the following two validity criteria: (1) the average value should be more than $\mathrm{OD}=0.8$ with the standard positive sample $(n=3)$, and (2) the average value should be less than $\mathrm{OD}=0.1$ with the standard negative sample $(\mathrm{n}=3)$. The feasibility of medical diagnosis of the electrochemical immunoassay based on switching peptides was demonstrated using the standard samples through serial dilution of a positive sample (included in the test kit) as well as the standard hHBsAg samples spiked in human serum. To compare the immunoassay results, fluorescence-labeled switching peptides were used for the same immunoassay, and a fluorescence spectrometer (Model: Victor X5) from PerkinElmer Inc. was used for the quantification of the fluorescence-labeled switching peptides. The chemiluminescence signal from the conventional immunoassay was measured using a commercial luminometer based on photomultiplier tube (Berthold Technologies GmbH \& Co., KG, Germany), and the chromogenic signal was measured using an ELISA reader (VersaMax; Molecular Devices Co., Sunnyvale, CA, USA). Statistical analyses of the immunoassay results from the electrochemical one-step immunoassay and the conventional immunoassays were performed using MedCalc software (version: 18.6) from MedCalc Software bvba (Ostend, Belgium). 
Figure S5 Electrochemical one-step immunoassay of human hepatitis B surface antigen (hHBsAg) with $\mathrm{L} 1-\mathrm{Fc}$ and $\mathrm{H} 2-\mathrm{Fc}$.
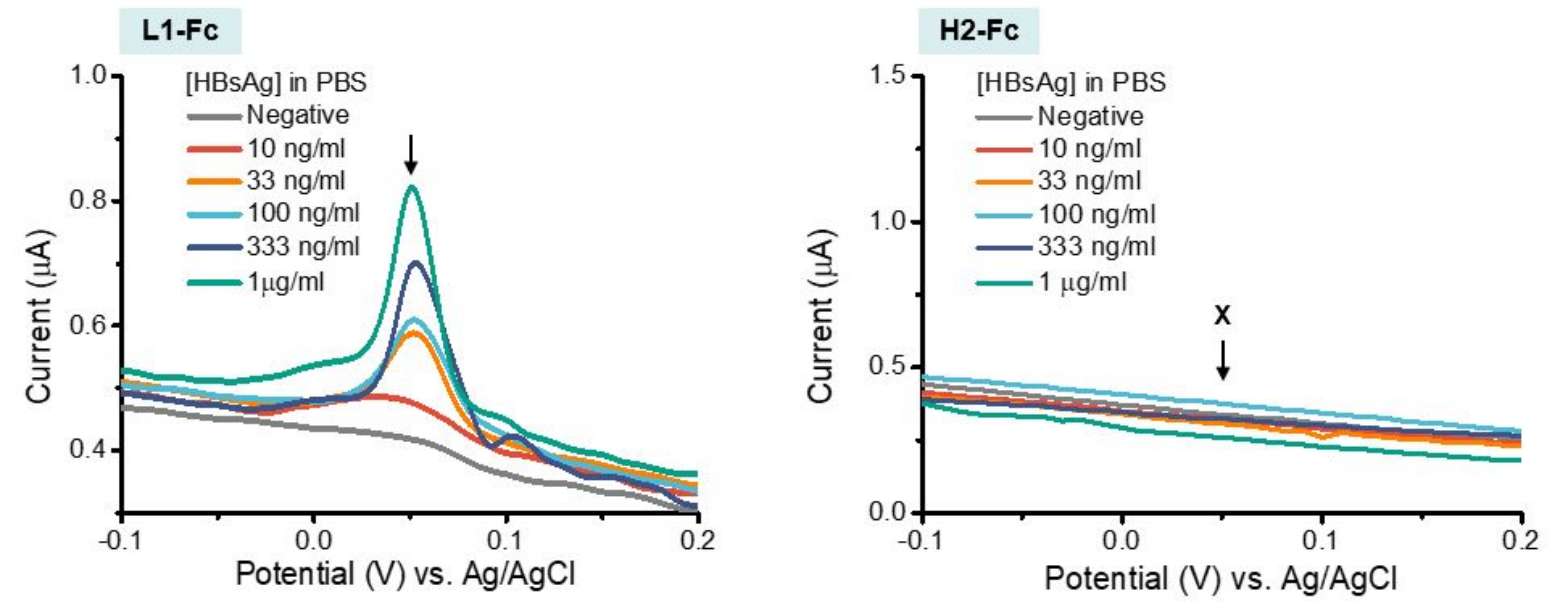